\title{
Evaluation of Serum Neurokinin A Level in Patients with Psoriasis Running Head
}

\author{
F.M.El-Esawy ${ }^{1}$, N.A.Abdelhafiz ${ }^{1}$, E.M.Akl ${ }^{1}$ and D.I.Khalaf ${ }^{2}$
}

${ }^{1}$ Dermatology and Andrology Dept., Faculty of Medicine, Benha Univ., Benha, Egypt

${ }^{2}$ Clinical and Chemical Pathology Dept., Faculty of Medicine, Benha Univ., Benha, Egypt

E-Mail:engmhmdelsayed85@gmail.com

\begin{abstract}
To evaluate serum level of neurokinin A in psoriatic patient and its correlation with disease severity Psoriasis is a complex chronic immune-mediated disease involves skin and joints. It involves inflammatory and hyper proliferative processes in the epidermis and upper part of the dermis. The tachykinins are named to their capacity on quickly animate withdrawal from claiming intestinal muscle, as opposed of the slower acting bradykinins. Neuorokinin a (substance K, neurokinin $\alpha$, neuromedin L), which is profoundly homologous should supstance $\mathrm{p}$, might have been recognized as a action to extracts of porcine spinal line that invigorated withdrawal for guinea pig ileum. Human keratinocytes express NK1R Also NK2R. NKA control those ability of keratinocytes will serve Similarly as cytokine processing plants Eventually Tom's perusing directing processing for proinflammatory cytokines.

This examine incorporated 84 members separated under two aggregations; bunch An incorporated 54 patients diagnosed clinically for psoriasis What's more one assembly b incorporated 30 ( agdistis and sex matched) clearly sound volunteers as An control. Serum level about NKA might have been measured utilizing elisa system to constant psoriatic patients What's more contrasted with control one assembly the comes about for our contemplate uncovered that patients needed secondary statistically huge higher NKA $(p<0.001)$ over control bunch.
\end{abstract}

Key words: Psoriasis, Tachykinins, NKA.

\section{Introduction}

Psoriasis will be an intricate incessant immune-mediated infection includes skin What's more joints. It includes incendiary and hyper proliferative forms within those epidermis Furthermore upper and only the dermis. There is An obsessive coordinated effort between intrinsic Furthermore gained resistance bringing about the generation from claiming cytokines, chemokines, development factors, bond atoms and neuropeptides [1]. A percentage Components referred to will trigger psoriasis incorporate smoking, liquor consumption, body impostor list (BMI), trauma (Koebner phenomenon), infection, endocrine disorders, medications (e. G. Beta blockers, antimalarials), Weight Also intense withdrawal for systemic alternately powerful topical anesthesia corticosteroids [2]. Anxiety activates dendritic phones prompting those arrival about neuromediators What's more catecholamines by means of those nerve endings in the skin, helping of the worsening of dermatological issue [3]. Those tachykinins would named for their capability should quickly invigorate withdrawal from claiming intestinal muscle, as opposed of the slower acting bradykinins. Neuorokinin An (substance K, neurokinin $\alpha$, neuromedin L), which will be profoundly homologous should supstance $p$, might have been distinguished Concerning illustration an action for extracts from claiming porcine spinal line that fortified withdrawal about guinea pig ileum. [4]. Mankind's keratinocytes express NK1R Also NK2R. NKA control those limit for keratinocytes should serve Similarly as cytokine industrial facilities by managing generation of proinflammatory cytokines. [5]. NKA-positive nerve fibers innervate the vasculature of the shallow dermis, the place tachykinins initiate those NK1R ahead endothelial units for postcapillary venules on animate plasma extravasation, granulocyte infiltration, and arrival of proinflammatory mediators (neurogenic inflammation) [6]. Surprisingly, NK2R antagonists improved the incendiary response, while NK2R agonists required those inverse effect, suggesting An protective part of for those NK2R [4].

\section{Materials and Methods \\ 2.1 The Study Population}

This is a case-control ponder. The current ponder needed been led between december 2018 will february 2019. After those endorsement Toward research council toward staff for Medicine, Benha school. Those ponder included 84 subjects that were haphazardly chose from the individuals going to the dermatology Outpatient's facility toward Benha school Hospital, staff from claiming Medicine, Benha University, Qalyobia, egypt. Former should start of the study, each liable might have been educated regarding those point of the study Also a educated assent might have been got from each distinctive in the recent past test gathering. They were partitioned under two aggregations; bunch a included 54 patients diagnosed clinically with psoriasis (PASI) score more than 8 . Period more than 18 a considerable length of time of age. Span about psoriasis more than 6 months. Also one assembly b incorporated 30 ( agdistis What's more sex matched) clearly sound volunteers Likewise a control.

\subsection{ELISA Assays of NKA}

Quantitative determinations of serum NKA were achieved using a double-antibody sand wich Enzyme Linked Immune Sorbent Assay technique (ELISA) was used to detect serum level of NKA using a commercial Human survivin ELISA Kit for research use only .

\subsection{Statistical Analysis}

The collected data was revised, coded, tabulated and introduced to a PC using Statistical package for Social Science (IBM Corp. Released 2011. IBM SPSS Statistics for Windows, Version 20.0. Armonk, NY: IBM Corp.). Data were presented and suitable analysis was done according to the type of data obtained for each parameter.Student $\mathrm{T}$ Test was used to assess the 
statistical significance of the difference between two study group means.For the comparison of the three groups' means, one way analysis of variance (ANOVA) was used. Chi-Square test was used to examine the relationship between two qualitative variables. Fisher's exact test: was used to examine the relationship between two qualitative variables when the expected count is less than 5 in more than $20 \%$ of cells. Correlation analysis: To assess the strength of association between two quantitative variables. The correlation coefficient defines the strength and direction of the linear relationship between two variables. $p$ is significant if $<0.05$ at confidence interval $95 \%$.

\section{Results}

This study included 84 subjects,54psoriatic patients and 30 normal subjects as control. the mean age with patients was $52 \pm 13$ range(range, 22-75) years, while in control it was $49 \pm 7$ range (22-60) years. The patients group included $35(64.8 \%)$ male and $19(35.2 \%)$ female, while controls included $13(43.3 \%)$ male and 17 (56.7\%) female. There were $17(31.5 \%)$ smokers among psoriatic patients while eight $(26.7 \%)$ controls were smokers. The mean BMI in psoriatic patients was $28.6 \pm 3.6 \mathrm{~kg} / \mathrm{m} 2$ while among controls was $28.7 \pm 2.76 \mathrm{~kg} / \mathrm{m} 2$. There was no significant difference between both groups as regard smoking and BMI.

Table (1) Socio-demographic and clinical characteristics of patients and controls .

\begin{tabular}{lccccc}
\hline & & Group I(n = 54) & Group II(n= 30) & Test & P value \\
\hline $\begin{array}{l}\text { Age } \\
\text { (Years) }\end{array}$ & Mean $\mathbf{n}$ SD & $\mathbf{5 2} \pm \mathbf{1 3}$ & $\mathbf{4 9} \pm \mathbf{7}$ & $\mathbf{t}=\mathbf{- 1 . 4 9 4}$ & $\mathbf{0 . 1 3 9}$ \\
Smoking & & & & & \\
nMI & $\mathrm{n}(\%)$ & $17(31.5)$ & $8(26.7)$ & $\mathrm{X} 2=0.214$ & 0.644 \\
Geander & Mean \pm SD & $28.6 \pm 3.6$ & $28.7 \pm 2.7$ & $\mathrm{t}=0.207$ & 0.837 \\
& Males n $(\%)$ & $35(64.8)$ & $13(43.3)$ & $\mathrm{X} 2$ & $\mathrm{p}$ \\
& Females n $(\%)$ & $19(35.2)$ & $17(56.7)$ & 3.634 & 0.057 \\
\hline
\end{tabular}

\section{Disease characteristics in cases group}

Family history was found positive in $18.5 \%$ of cases. A regard age of onset, its mean was 37 years with SD of 14 years. Majority of cases showed intermittent course (94.4\%). Mean duration of disease was 15 with SD of 13. As regard PASI score, its mean was 18.5 with SD of
7. $7.4 \%$ of cases showed nail involvement. $1.9 \%$ showed positive history of arthritis. $98.1 \%$ showed positive history of previous treatment. $24.1 \%$ showed positive history of DM and $31.5 \%$ showed positive history of hypertension.

Table (2) Disease characteristics in cases group.

\begin{tabular}{lll}
\hline Disease characteristics & & \\
\hline +ve family history & $\mathrm{n}(\%)$ & $10(18.5)$ \\
Age of onset & Mean \pm SD & $37 \pm 14$ \\
Course & Progressive & $3(5.6) 51(94.4)$ \\
& Intermittent & \\
Duration & Mean \pm SD & $15 \pm 13$ \\
Clinical type & Plaque & $54(100.0)$ \\
PASI score & Mean \pm SD & $18.5 \pm 7$ \\
Nail involvement & $\mathrm{n}(\%)$ & $4(7.4)$ \\
History of arthritis & $\mathrm{n}(\%)$ & $1(1.9)$ \\
History of previous treatment & $\mathrm{n}(\%)$ & $53(98.1)$ \\
History of DM & $\mathrm{n}(\%)$ & $13(24.1)$ \\
History of HTN & $\mathrm{n}(\%)$ & $17(31.5)$ \\
\hline
\end{tabular}

DM = Diabetes mellitus HTN = Hypertension

The mean NK-A level was $361.5 \pm 82$ in psoriatic patients while in controls $293.7 \pm 81.2$. NK-A was significantly higher in cases than controls . $P$ value was $<0.001$ ROC analysis was done for NK-A in diagnosing psoriasis. It revealed a significant area under curve of 0.7 with $95 \%$ confidence interval ranging from 0.584 to 0.815 . Best cutoff point was $>262.7$ At which sensitivity and specificity were $92.7 \%$ and $36.7 \%$ respectively. $\mathrm{P}$ value was 0.003 .

Regarding NK-A , there was no significant difference between males in both groups . P value was
0.107 NK-A was significantly higher in female cases (360.1) compared to female controls (280.4). P value was 0.019 .There was no significant difference in NK-A between patients with different disease durations. $\mathrm{P}$ value was 0.848 .There were no significant difference in NK-A between patients with different PASI scores. $\mathrm{P}$ value was 0.706 NK-A showed non-significant difference between smokers and non-smokers ( $P$ value was 0.237 ) and between those with positive and negative family history ( $\mathrm{P}$ value was 0.617 ) 
Table (3 )comparison between NK-A level in patients and controls.

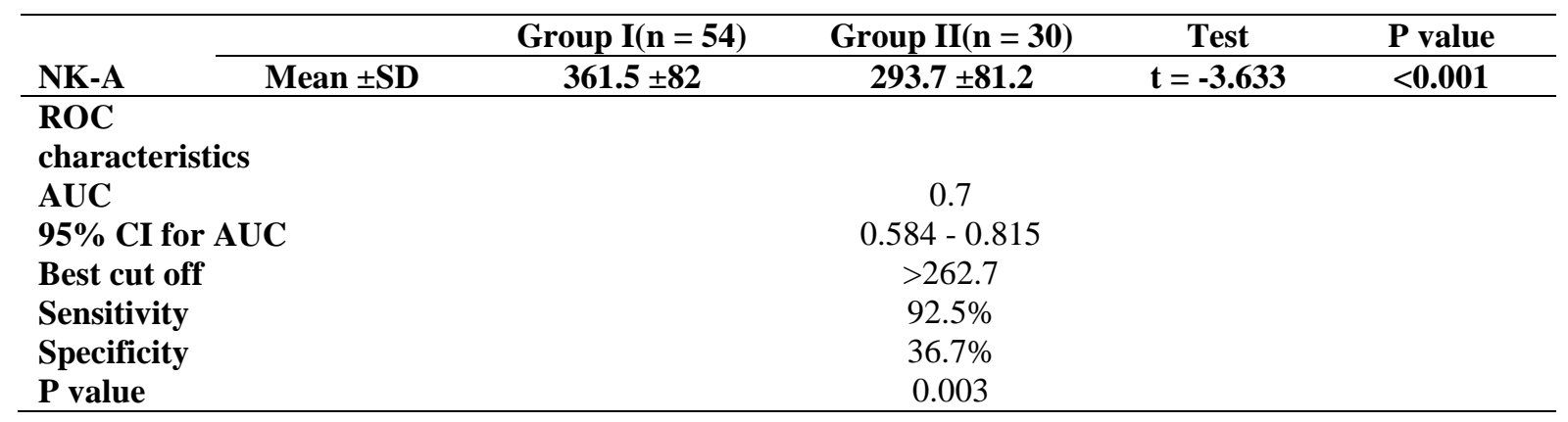

$\mathrm{AUC}=$ Area Under Curve 95\% CI = 95\% confidence interval.

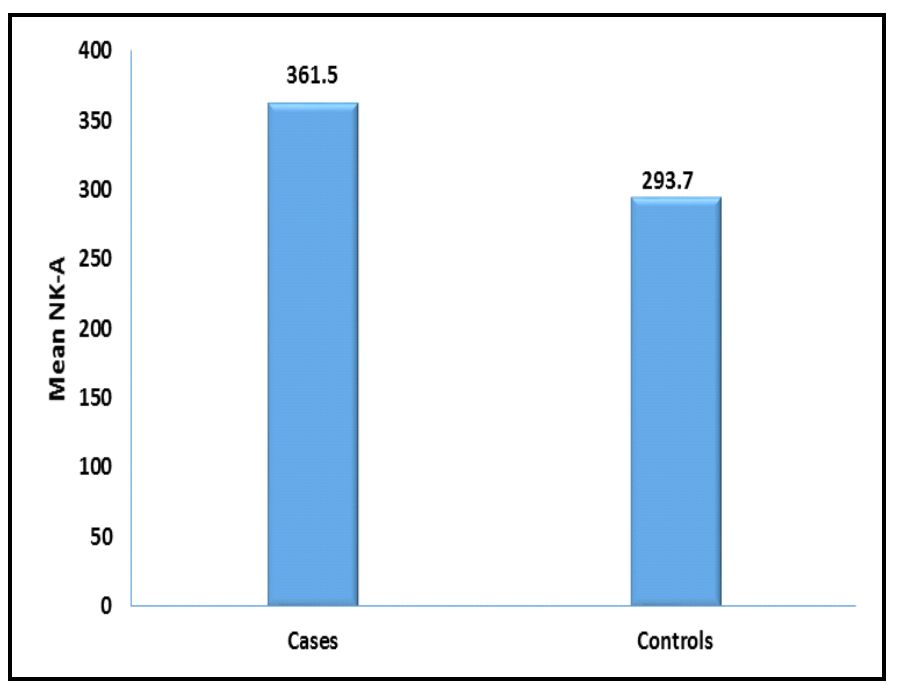

Fig (1) AMean NK-A in both groups

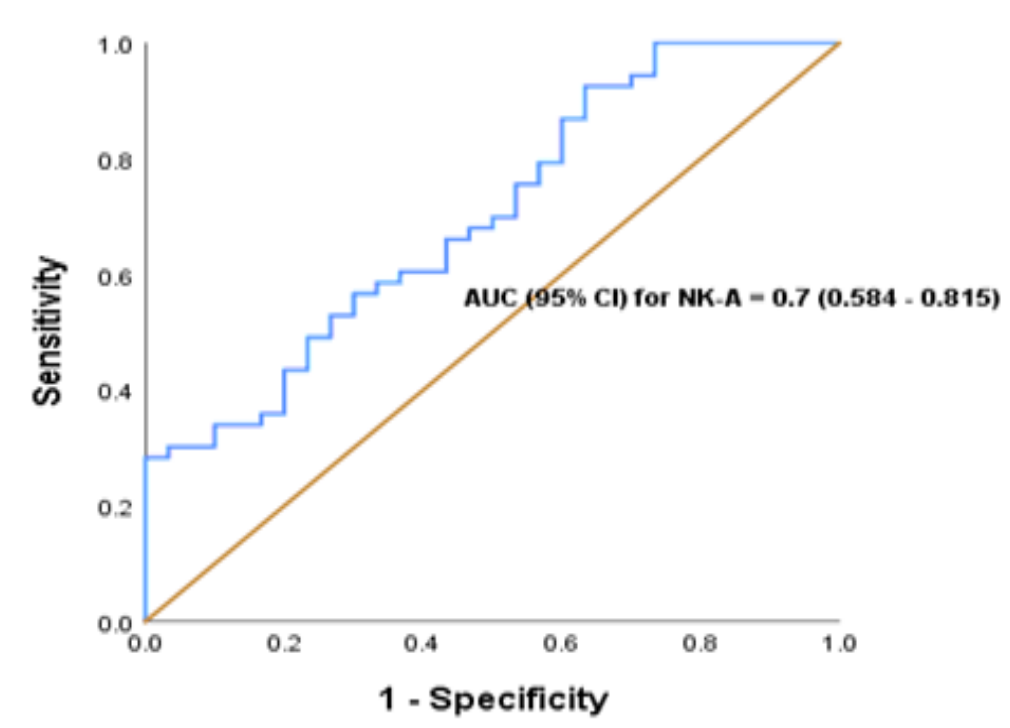

Fig ( 2) ROC curve for NK-A in diagnosing psoriasis 
Table (3) comparison between NK-A level in male patients and male controls

\begin{tabular}{|c|c|c|c|c|c|c|c|c|}
\hline & \multicolumn{2}{|c|}{ Male cases $(n=35)$} & \multicolumn{3}{|c|}{ Male controls $(n=13)$} & & & \\
\hline \multirow{3}{*}{ NK-A } & \multirow{2}{*}{$\begin{array}{l}\text { Mean } \\
362.2\end{array}$} & $\pm \mathrm{SD}$ & Mean & \multicolumn{2}{|r|}{$\pm \mathrm{SD}$} & \multicolumn{2}{|c|}{$\mathrm{Z}$} & \multirow{2}{*}{$\begin{array}{c}\mathrm{P} \text { value } \\
0.107\end{array}$} \\
\hline & & 80.5 & 311 & & 71.9 & \multicolumn{2}{|c|}{-1.612} & \\
\hline & \multicolumn{2}{|c|}{ Female cases $(n=18)$} & \multicolumn{3}{|c|}{ Female controls $(\mathrm{n}=17)$} & \multirow{2}{*}{\multicolumn{2}{|c|}{ Z }} & \\
\hline \multirow{3}{*}{ Nk-A } & \multicolumn{2}{|l|}{ Mean } & \multicolumn{2}{|c|}{ Mean } & $\pm \mathrm{SD}$ & & & $P$ value \\
\hline & 360.1 & 87.2 & 280. & & 87.4 & \multicolumn{2}{|c|}{-2.343} & 0.019 \\
\hline & \multicolumn{2}{|c|}{ Duration $<5(\mathrm{n}=10)$} & \multicolumn{2}{|c|}{$5-10(\mathrm{n}=15)$} & \multicolumn{3}{|c|}{$>10(\mathrm{n}=29)$} & \\
\hline \multirow{4}{*}{ NK-A } & Mean & $\pm \mathrm{SD}$ & Mean & $\pm \mathrm{SD}$ & Mean & $\pm \mathrm{SD}$ & KW & $P$ value \\
\hline & 367 & 86.9 & 344.7 & 72 & 368.5 & 86.7 & 0.329 & 0.848 \\
\hline & \multicolumn{2}{|c|}{ PASI $8-15(n=20)$} & \multicolumn{2}{|c|}{$16-22(\mathrm{~N}=19)$} & \multicolumn{2}{|c|}{$>22(\mathrm{n}=15)$} & & \\
\hline & Mean & $\pm \mathrm{SD}$ & Mean & $\pm \mathrm{SD}$ & Mean & $\pm \mathrm{SD}$ & KW & $P$ value \\
\hline \multirow{4}{*}{$\begin{array}{l}\text { NK-A } \\
\text { Smoking }\end{array}$} & 348.7 & 68.7 & 363 & 92.5 & 377.6 & 87.3 & 0.695 & 0.706 \\
\hline & \multicolumn{2}{|c|}{ Yes $(\mathrm{n}=17)$} & \multicolumn{2}{|c|}{382.2} & 89.1 & \multicolumn{2}{|c|}{$Z=-1.182$} & 0.237 \\
\hline & \multirow{2}{*}{\multicolumn{2}{|c|}{ No $(\mathrm{n}=37)$}} & \multicolumn{2}{|c|}{351.7} & 77.8 & \multirow{2}{*}{\multicolumn{2}{|c|}{ Test }} & \\
\hline & & & & & $\pm \mathrm{SD}$ & & & $P$ value \\
\hline \multirow{2}{*}{$\begin{array}{l}\text { +veFamily } \\
\text { history }\end{array}$} & \multirow{2}{*}{\multicolumn{2}{|c|}{ Yes $(n=10)$}} & \multicolumn{2}{|c|}{375.8} & 89.5 & \multirow{2}{*}{\multicolumn{2}{|c|}{$Z=-0.500$}} & 0.617 \\
\hline & & $=44$ & & & 89.9 & & & \\
\hline
\end{tabular}

Mann Whitney U test was used

\section{Discussion}

Psoriasis is An skin-specific T-cell-mediated immune system disease, epidermal development factors, nerve development factors, bond factors, chemokines, neuropeptides, What's more T-cell receptors need aid included done its pathogenesis [7]. NKA is introduce over essential tactile nerves in the skin. Tachykininpositive nerve fibers supply the dermis Furthermore epidermis and also innervate dermal blood vessels, keratinocytes, massorete cells, dendritic cells, and hair follicles [8]. Those point from claiming this consider might have been to assess serum level from claiming NKA. This contemplate included 84 subjects, 54psoriatic patients What's more 30 ordinary subjects Concerning illustration control. In the current contemplate there were $17(31.5 \%)$ smokers. In this contemplate imply BMI 28. $6 \pm 3$. 6. There might have been no critical Contrast between both gatherings Concerning illustration see smoking auto Also BMI.

As opposed with this study, in a pooled examination from claiming 25 case-control studies, those chances degree for psoriasis Around smokers might have been 1 . 78. A dose-effect relationship is Additionally recorded. The hazard of occurrence psoriasis might have been 1 . 81 On the individuals who smoked haddock 1-14 smokes for every day, What's more 2. 29 clinched alongside the individuals who smoked haddock $\geq 25$ smokes for every day. Smoking auto likewise effects on the clinical seriousness for psoriasis, its light of medicine. [10] Done [11] stated that $1 \mathrm{~kg} / \mathrm{m} 2$ increment for BMI might have been connected with $4 \%$ higher chances about psoriasis $[9,10]$. In the current consider , 18. 5\% for instances indicated sure family history of psoriasis. Over aggrement for current consider [12] discovered that An family history from claiming psoriasis might have been determinedly connected with psoriasis, the multivariate chances proportion being 7. 0 for subjects who news person a historical backdrop of the ailment done folks alternately siblings. With current study [13] discovered that "around 1393 patients in the database (mean age: $48 \pm 13$. 1; 63. $2 \%$ female) 444 (31. $9 \%$ patients required a family history of psoriasis. $[11,12]$. In the present study, intend period from claiming onset $37 \pm 14$ quite some time. Previously, [15] (Psoriasis need been subclassified as stated by agdistis from claiming onset. Initial onset psoriasis (also alluded will Similarly as kind I) need onset in front of those agdistis from claiming 40 years, with top onset during 16-22 quite some time from claiming age, and comprises $70 \%$ of know psoriatic. Late-onset psoriasis, likewise termed sort ii psoriasis, indicates onset during or after agdistis 40 years, with An top agdistis for onset between 57 Furthermore 60 quite some time.

In this ponder NK-A might have been essentially higher On cases contrasted with controls. Roc dissection might have been accomplished for NK-A over diagnosing psoriasis, it uncovered An noteworthy zone under bend of 0.7 with $95 \%$ certainty interim extending from 0.584 to 0.815 . Logistic relapse might have been accomplished for prediction from claiming psoriasis. NK-A might have been a noteworthy predictor for psoriasi. NK-A indicated non-significant distinction the middle of guys Also females, the middle of smokers What's more non-smokers Furthermore the middle of the individuals with certain Furthermore negative family history. [13]. Done [16] biopsies were gotten from 28 patients for incessant plaque psoriasis and contrasted with biopsies of 10 controls. The tests were taken from for immunohistochemistry staining, An radioimmunoassay. NKA-immunoreactive nerve fibers, that found intra epidermal were huge higher for number for lesional compared for solid control skin[14]. 
In the present study, there might have been no noteworthy Contrast between guys to both gatherings Similarly as see NK-A. NK-A might have been essentially higher over female situations contrasted with female controls. There might have been no huge Contrast in NK-A between patients for different malady durations. There were no critical distinction On NK-A between patients with distinctive PASI scores. NK-A demonstrated noteworthy certain correspondence with ldl What's more cholesterol.

\section{Summary}

This ponder included 84 subjects,54psoriatic patients Also 30 typical subjects Concerning illustration control. The intend period for patients might have been $52 \pm 13$ range(range, 22-75) years, same time On control it might have been $49 \pm 7$ range (22-60) quite some time. There might have been no huge Contrast the middle of both Assemblies as see agdistis. $(\mathrm{p}=0.139$ ( the patients gathering incorporated $35(64.8 \%)$ male and $19(35.2 \%)$ female, same time controls incorporated 13 (43. $3 \%)$ male Furthermore 17 (56. 7\%) females there might have been no noteworthy Contrast between both gatherings as respect sexual orientation. ( $p=0$. 057). Those comes about of our examine uncovered that patients required secondary statistically noteworthy higher NKA ( $\mathrm{p}<0.001)$ for imply $\pm \operatorname{SD}(361.5 \pm 82)$ over control one assembly with mean $\pm \operatorname{SD}(293.7 \pm 81$. $)$.

\section{Conclsions}

From the result of our study, it is concluded that NKA level was elevated in psoriasis .

\section{Recommendations}

Larger sample are needed to evaluate serum level of NKA in patients with psoriasis.

study the level of NKA in the psoriatic lesions by immunohistopathology.

\section{References}

[1] S .Sundarrajan , M.Arumugam , Weighted gene coexpression based biomarker discovery for psoriasis detection. Gene, Vol.593(1), PP.225-234,2016.

[2] K .H .Basavaraj , N .M. Ashok , R. Rashmi , T .K. Praveen, The role of drugs in the induction and/or exacerbation of psoriasis. Int $\mathbf{J}$ Dermatol, Vol.49 (12), pp..1351-1361,2016.

[3] Slominski, J. Wortsman, T .Luger, Corticotropin releasing hormone an proopiomelanocortin involvement in the cutaneous response to stress. Physiol Rev, Vol.80(3), PP.979 - 1020,2000.
[4] M. S. Steinhoff , B. von Mentzer , P. Geppetti , C.Pothoulakis , N.W . Bunnett, Tachykinins and their receptors: contributions to physiological control and the mechanisms of disease. Physiological reviews , Vol.94(1), pp..25-301,2014.

[5] D. Roggenkamp , S .Kopnick , F .Stab , H .Wenck , M. Schmelz ,

[6] Epidermal nerve fibers modulate keratinocyte growth via neuropeptide signaling in an innervated skin model. J Invest Dermatol , Vol.133, pp..1620 1628,2013 .

[7]

.Botz , A .Imreh , K .Sandor , K.Elekes , J.Szolcsanyi, Role of pituitary adenylate-cyclase activating polypeptide and Tac1 gene derived tachykinins in sensory, motor and vascular functions under normal and neuropathic conditions. Peptides., Vol.43(7), pp..105-112,2013.

[8] X. Xu , H. Y. Zhang, The Immunogenetics of Psoriasis and Implications for Drug Repositioning. Int J Mol Sci , Vol.18(12), pp..2650-2655,2017.

[9] D. Roosterman , T .Goerge , S .W. Schneider , N .W .Bunnett , M. Steinhoff, Neuronal control of skin function: the skin as a neuroimmunoendocrine organ. Physiol Rev, Vol.86(4), pp..1309-79,2006.

[10] L.Naldi , Psoriasis and smoking: links and risks. Psoriasis (Auckland, NZ), Vol. 6, pp.65,2016.

[11] B . A.Aggrey, B.Brumpton, J.Tyrrell, S.Watkins, E. H.Modalsli, C.Celis-Morales, M.Løset, Evidence of a causal relationship between body mass index and psoriasis: A mendelian randomization study. PLoS medicine, Vol. 16(1), pp.1002739,2019.

[12] L .Naldi , L .Peli , F .Parazzini , C . F. Carrel , Psoriasis Study Group of the Italian Group for Epidemiological Research I Dermatology, Vol.5(3), pp..50-13,2001.

[13] D .Solmaz , S .Bakirci , G. Kimyon , E. Kasapoglu Gunal, A.Dogru ,

[14] The impact of having family history of psoriasis or psoriatic arthritis on psoriatic disease. Arthritis care \& research, Vol.70(5), pp..60-15,2019.

[15] R. Queiro , P. Tejon , S. Alonso , P. Coto , Age at disease onset: a key factor for understanding psoriatic disease. Rheumatology, Vol.53(7), pp.1178$1185,2013$.

[16] Amatya, Study of pruritus in psoriasis vulgaris: Role of tachykinins. Institutionen för medicin/Department of Medicine, Vol.40(18), pp..110-125,2009. 